\title{
THE ROLE OF THE COMMUNICATIONAL POLICY IN THE MARKETING ACTIVITY OF CONSTRUCTION ORGANIZATIONS
}

\author{
Iulian Patriche, Ph.D., ipatsib89@yahoo.com \\ Central Office of State for Special Issues
}

\begin{abstract}
The specific elements of the communicational policy in the construction field reports on the cooperation with all the factors which intervene in the accomplishment and capitalization of the construction, outline of the publicity concept, way of including the communication costs in the price, making and translation of the publicity messages, involvement of the distribution partners in the making and translation of the promotion activities, as well as determination of the publicity space. At the same time, the public relations have a special importance in the construction field, because of the high number of actors that intervene in the specific process and which constitute the public of the domain organization: consumers, strategic partners and other collaborators, public authorities, media, share-holders, the general public, etc. The construction organization must insure a specific relational system, based on programs of actions for every category of actors.
\end{abstract}

Construction organizations use various promotional approaches to communicate with target markets. To define and examine the role of the communication policy in the construction field, we must understand how promotion works and the meaning of the communication process in this economic domain. We must discuss the major types of promotional methods and the factors that influence a construction organization's decision to use specific methods of communication.

The communication process consists in two components: the promotional communication - also known as promotion - and the permanent communication. In this case we discus about the role of the promotion in the market activity.

The role of promotion is to communicate with individuals, groups or organizations to directly or indirectly facilitate exchanges by informing and persuading one or more of the audiences to accept a construction organization's products. One lung-run purpose of promotion is to influence and encourage buyers to accept or adopt construction products, services and ideas.

Companies indirectly facilitate exchanges by focusing information about organization's activities and products on interest groups (such as environmental and consumer groups), current and potential investors, regulatory agencies and society in general. Like all the organizations, construction plants communicate to facilitate satisfying exchanges.

Promotion can play a comprehensive communication role. Some promotional activities, such as publicity and public relation, can be directed toward helping a construction company justify its existence and maintain positive, healthy relationships between itself and various groups in the marketing environment.

Although a company can direct a single type of communication - such as an advertisement - toward numerous audiences, constructors often design a communication precisely for a specific target market. A construction firm frequently communicates several different messages concurrently, each to a different group.

To gain maximum benefit from promotional efforts, construction organizations must make every effort to properly plan, implement, coordinate and control communications. Effective promotional activities are based on information from the marketing environment, 
often obtained from an organization's marketing information system. How effectively construction plants can use promotion to maintain positive relationships depends largely on the quantity and quality of information an organization takes in.

In the construction field, the promotional communication is much difficult to realize, because of some disturbing elements, such as economic and cultural differences, different tastes, attitudes and habits and the large variety of actors that intervenes in the market process of a construction company.

Communication can be viewed as the transmission of information. For communication to take place, however, both the sender and the receiver of the information must share some common ground. They must share a common understanding of the symbols used to transmit information. Thus we define communication as a sharing of meaning. Implicit in this definition is the notion of transmission of information because sharing necessitates transmission. In the construction field, information is mostly technique and that involves specific methods to transmit the ideas from the companies to their audience.

Communication begins with a source. The source is the construction organization that has a meaning it intends and attempts to share with an audience. A receiver is the individual, group or organization that decodes a coded message. An audience is two or more receivers who decode a message. To transmit meaning, a source must convert the meaning into a series of signs that represent ideas or concepts. This is called the coding process or encoding. When coding meaning into a message, a source must take into account certain characteristics of the receiver or audience. First, to share meaning, the source should use signs that are familiar to the receiver or audience. Construction organizations who understand this fact realize how to know their target market and to make sure that an advertisement, for example, is written in language that the target market can understand. Thus it is important that people understand the language used in promotion. Second, when coding a meaning, a source should try to use signs that the receiver or audience uses for referring to the concepts the source intends. Construction plants should generally avoid signs that can have several meanings for an audience. To share a coded meaning with the receiver or audience, a source must select and use a medium of transmission. A medium of transmission carries the coded message from the source to the receiver or audience. When a source chooses an inappropriate medium of transmission, several problems may arise. A coded message may reach some receivers, but not the right ones. Coded messages may also reach intended receivers in an incomplete form because the intensity of the transmission is weak. In the decoding process, signs are converted into concepts and ideas. Seldom does a receiver decode exactly the same meaning that a source coded. When the decoding results are different from what was coded, noise exists. Noise has many sources and may affect any or all parts of the communication process in the construction field. When a source selects a medium of transmission through which an audience does not expect to receive a message, noise is likely to occur. Noise sometimes arises within the medium of transmission itself. Noise also occurs when a source uses a sign that is unfamiliar to the receiver or that has a different meaning from the one the source intended. Noise also may originate in the receiver. A receiver may be unaware of a coded message because his perceptual processes block it out. The receiver's response to a message is feedback to the source. The source usually expects and normally receives feedback, although it may not be immediate. During feedback, the receiver or audience is the source of a message that is directed toward the original source, which then becomes a receiver. Feedback is coded, send through a medium of transmission, and is decoded by the receiver, the source of the original communication. It is logical, then, to think about communication as a circular process. During face-to-face communication, such as a constructor - beneficiary situation, both verbal and nonverbal feedback can be immediate. Instant feedback lets communicators in the construction field adjust their message quickly to improve the effectiveness of their 
communication. Each communication channel has a limit on the volume of information it can handle effectively. This limit, called channel capacity, is determined by the least efficient component of the communication process.

In the construction marketing, several types of promotional methods can be used to communicate with individuals, groups and organizations. When a construction organization combines specific ingredients to promote a particular product (a type of a building, a particular construction service) that combination constitutes the promotion mix for that product. The four possible ingredients of a promotion mix are advertising, personal selling, publicity and sales promotion. Also, in the construction domain we can mention as promotion mix components the direct communication and exhibitions participation.

Advertising is a paid form of non personal communication about an construction organization and its products that is transmitted to target audience through a mass medium such as television, radio, newspapers, magazines, direct mail, mass transit vehicles, outdoor displays or catalogs. Construction organizations use advertising to promote specific products, services, ideas and issues. Because it is highly flexible, advertising offers the options of reaching an extremely large target audience or focusing on a small, precisely defined segment of the population. Advertising offers several benefits. It can be an extremely cost-efficient promotional method because it can reach a vast number of people at a low cost per person. Advertising also lets the user repeat the message a number of times. The visibility that an organization gains from advertising enhances the firm's public image. Advertising also has several disadvantages. Even though the cost per person reached may be low, its absolute price can be extremely high, especially for commercials during popular television shows. These high costs can limit and, sometimes, prevent, the use of advertising in a promotion mix. Moreover, advertising rarely provides rapid feedback. Measuring its effects on sales is difficult and it ordinarily has less persuasive impact on costumer than personal selling.

Personal selling involves informing customers and persuading them to purchase products through communication in an exchange situation, to encompass the acceptance of ideas and issues. Personal selling has both advantages and limitation when compared with advertising. Advertising is general communication aimed at a relatively large target audience, whereas personal selling involves more specific communication aimed at one or several persons. Reaching one person through personal selling costs considerably more than it does through advertising, but personal selling efforts often have greater impact on construction customers. Personal selling also provides immediate feedback, which allows construction plants to adjust their message to improve communication. It helps them determine and respond to costumer's needs for information. When a construction specialist and a customer meet face to face, they use several types of interpersonal communication. Obviously, the predominating communication form is the technical language.

Publicity refers to non personal communication in news story form about a construction organization or its products or both, that is transmitted through a mass medium at no charge. Examples of publicity include magazine, newspaper, radio and television news stories about new construction projects and new products or personnel changes in organization. Although both advertising and publicity are transmitted through mass communication, the sponsor does not pay the media costs for publicity and is not identified. Nevertheless, publicity should never be viewed as free communication. There are clear costs associated with preparing news releases and encouraging media personnel to broadcast or print them. A construction firm that uses publicity regularly must have employees to perform these activities or obtain the services of a public relation firm or an advertising agency. Either way, the firm bears the costs of the activities. Publicity must be planned and implemented so that it is compatible with and supportive of, other elements in the promotion mix. However, 
publicity cannot always be controlled to the extent that other elements of the promotion mix can be.

Sales promotion is an activity or material that acts as direct inducement, offering added value or incentive for the product, to subcontractors, sales-persons or consumers. Examples of sales promotion include bonuses and contents used to enhance the sales of a product. The term sales promotion should not be confused with promotion. Sales promotion is but a part of the more comprehensive area of promotion, encompassing efforts other than personal selling, advertising and publicity. Currently, construction organizations spend about one and a half times as much on sales promotion as they do on advertising. Sales promotion appears to be growing in use more than advertising. Construction plants frequently rely on sales promotion to improve the effectiveness of other promotion mix ingredients, especially advertising and personal selling. In the construction filed marketers design sales promotion to produce immediate, short-run sales increases. Generally, if a company employs advertising or personal selling, it either depends on them continuously or to them cyclically. However, a marketer's use of sales promotion tends to be irregular. We must also mention that many construction products are seasonal.

The direct communication involves direct marketing methods, involves the use of catalogs and technical booklets, also the use of bill boards and, most of all, involves the use of cybermarketing.

Exhibitions participation is a specific component of promotional mix in the construction field. Construction plants must focused on the characteristics exhibitions for this economic domain.

Now that we have discussed the basic components of a construction organization's promotion mix, we need to consider how that mix is created. We must examine what factors and conditions affect the selection of the promotional methods that a specific organization uses in its promotion mix for a particular construction product.

Construction organizations vary the composition of promotion mixes for many reasons. Although all ingredients can be included in a promotion mix, frequently a marketer selects fewer than four. In addition, many construction firms that market multiple product lines use several promotion mixes simultaneously. An organization's promotion mix is not an unchanging part of the marketing mix. Marketers can and do change the composition of their promotion mixes. The specific promotion-mix ingredients employed and the intensity at which they are used depend on a variety of factors, including the organization's promotional resources, objectives and policies; characteristics of the target market; characteristics of the product; cost and availability of promotional methods.

The quality of a construction organization's promotional resources affects the number and relative intensity of promotional methods that can be included in a promotion mix. If a construction company's promotional budget is extremely limited, the firm is likely to rely on personal selling because it is easier to measure a person's contribution to sales than to measure the effects of advertising. In construction field, a business must have a sizable promotional budget if it is to use regional or national advertising and sales promotion activities. Organizations with extensive promotional resources usually can include more ingredients in their promotion mixes. However, having more promotional money does not imply that they necessarily will use a greater number of promotional methods. A construction organization's promotional objectives and policies also influence the types of promotion used. If a company's objective is to create mass awareness of a new type of a building, its promotion mix is likely to lean heavily toward advertising, sales promotion, and possibly publicity. If a company hopes to educate consumers about the features of durable product, such as a house, its promotion mix may combine a moderate amount of advertising, possibly 
some sales promotion efforts designed to attract customers and a great deal of personal selling because this method is an excellent way to inform customers about these types of products.

The size, geographic distribution and socioeconomic characteristics of a construction organization's target market also help dictate the ingredients to be included in a product's promotion mix. To some degree, market size determines the composition of the mix. If the size is quite limited, the promotion mix will probably emphasize personal selling, which can be quite effective for reaching small numbers of people. Construction organizations that sell to industrial markets and firms that market their products through only a few subcontractors frequently make personal selling the major component of their promotion mixes. When markets for a product consist of many customers, organizations use advertising and sales promotion because these methods can reach masses of people at a low cost per person. The geographic distribution of a firm's customers can affect the combination of promotional methods used. Personal selling is more feasible if a construction company's customers are concentrated in a small area than if they are dispersed across a vast region. When a company's customers are numerous and dispersed, advertising may be more practical. The distribution of a target market's socioeconomic characteristics, such as age, income or education, may dictate the types of promotional techniques that a marketer selects.

Generally, promotion mixes for construction products concentrate on personal selling. However, constructors do use some advertising to promote their products. Personal selling is used extensively for consumer durables such as buildings and other construction products. Publicity appears in promotion mixes for industrial goods and construction products. Marketers of highly seasonal products are often forced to emphasize advertising and possibly sales promotion, because off-season sales will not support an extensive year-round sales force. The price of a product also influences the composition of the promotion mix. Highpriced products - such as the construction products are - call for more personal selling because consumers associate greater risk with the purchase of such products and usually want the advice of a specialist. A further consideration in creating an effective promotion mix is the stage of the product life cycle. During the introduction stage a good deal of advertising may be necessary for construction products to make potential users aware of a new product. For many products, personal selling and sales promotion are helpful as well at this stage. Construction products often require a concentration of personal selling and some sales promotion efforts during the growth and maturity stages. In the decline stage, marketers usually decrease their promotional activities, especially advertising. Promotional efforts in the decline stage often center on personal selling and sales promotion efforts. The intensity of market coverage is still another factor affecting the composition of the promotion mix. When a product is marketed through intensive distribution, the firm depends strongly on advertising and sales promotion. Where marketers have opted for selective distribution, marketing mixes vary considerably as to type and amount of promotional methods. Items handled through exclusive distribution frequently demand more personal selling and less advertising. A product's use also affects the combination of promotional methods.

The costs of promotional methods are major factors to analyze when developing a promotion mix. Advertising and sales promotion efforts require large expenditures. If the efforts are effective in reaching extremely large number of people, the cost per individual reached may be quite small. Not all forms of advertising are expensive, however. Many small, local construction businesses advertise their products through local newspapers, magazines, radio and television stations, and outdoor and transit signs. Another consideration that marketers must explore when formulating a promotion mix is the availability of promotional techniques.

Another element that construction organizations should consider when they plan a promotion mix is whether to use a push policy or a pull policy. With a push policy, the 
producer promotes the product only to the next institution down the marketing channel. For instance, in a marketing channel with subcontractors, the producer promotes to the subcontractor because in this case the subcontractor is the channel member just below the producer. Each channel member in turn promotes to the next channel member. A push policy normally stresses personal selling. Sometimes sales promotion and advertising are used in conjunction with personal selling to push the products down through the channel. A firm using a pull policy promotes directly to consumers with the intention of developing a strong consumer demand for the products. It does so through advertising and sales promotion that helps construction plants build and maintain market share. Because consumers are persuaded to seek the products to the subcontractors, subcontractors will in turn go to the producer to buy the products. The policy is thus intended to "pull" the goods down through the channel by crating demand at the consumer level.

\section{Bibliography:}

1. Balaure, V. (coordonator): Tehnici promoționale. Probleme, analize, studii de caz, Editura Uranus, Bucureşti, 2002

2. Balaure, V. (coordonator): Marketing - ediția a II-a revăzută şi adăugită, Editura Uranus, Bucureşti, 1999

3. Bodinat (de), H.: Un pavé dans le marketing, les Éditions Jean-Claude Lattes, 1990

4. Boisdevésy, J.Ch.: Le marketing relationnel, les Éditions d'Organisation, Paris, 1998

5. Florescu, C., Mâlcomete, P., Pop, N.Al. (coordonatori): Marketing - Dicționar explicativ, Editura Economică, Bucureşti, 2003

6. Ford, D. (coordonator): Managing Business Relationship, John Wiley \& Sons, New York, 1998

7. Patriche, I.: Piața construcțiilor în România, Editura Uranus, Bucureşti, 2003

8. Piquet, G. (coordonator): La publicité, nerf de la communication, les Éditions d'Organisation, Paris, 1983

9. Pop, N.Al., Dumitru, I.: Marketing internațional, Editura Uranus, Bucureşti, 2001

10. Popescu, I.C.: Comunicarea în marketing, Editura Uranus, București, 2001

11. Samuel, J.L.: Publicitatea pe piața de afaceri, în lucrarea Marketing industrial, coordonator N. Hart, Editura Codecs, Bucureşti, 1994 
